\title{
Superelasticity by Reversible Variant Reorientation in a Ni-Mn-Ga Microwire with Bamboo Grains
}

Z.L. Wang ${ }^{1,2}$, P. Zheng ${ }^{1}$, Z.H. Nie ${ }^{2}$, Y. Ren ${ }^{3}$, Y.D. Wang ${ }^{4}$, P. Müllner ${ }^{5}$, D.C. Dunand ${ }^{1, *}$

${ }^{1}$ Department of Materials Science \& Engineering, Northwestern University, Evanston, IL 60208, USA

${ }^{2}$ School of Materials Science \& Engineering, Beijing Institute of Technology, Beijing 100081, China

${ }^{3}$ X-Ray Science Division, Argonne National Laboratory,

Argonne, IL 60439, USA

${ }^{4}$ State Key Laboratory of Advanced Metals and Materials, University of Science and Technology Beijing, Beijing 100083, China

${ }^{5}$ Department of Materials Science \& Engineering, Boise State University, Boise, ID 83725, USA

*Corresponding author: dunand@ @orthwestern.edu 


\begin{abstract}
The link between microstructure and mechanical properties is investigated for a superelastic Ni-Mn-Ga microwire with $226 \mu \mathrm{m}$ diameter, created by solidification via the Taylor method. The wire, which consists of bamboo grains with tetragonal martensite matrix and coarse $\gamma$ precipitates, exhibits fully reversible superelastic behavior up to $4 \%$ tensile strain. Upon multiple tensile load-unload cycles, reproducible stress fluctuations of $\sim 3 \mathrm{MPa}$ are measured on the loading superelastic stress plateau of $\sim 50 \mathrm{MPa}$. During cycles at various temperatures spanning -70 to 55 ${ }^{\circ} \mathrm{C}$, the plateau stress decreases from 58 to $48 \mathrm{MPa}$ near linearly with increasing temperature. Based on in-situ synchrotron X-ray diffraction measurements, we conclude that this superelastic behavior is due to reversible martensite variant reorientation (i.e., reversible twinning) with lattice rotation of $\sim 13^{\circ}$. The reproducible stress plateau fluctuations are assigned to reversible twinning at well-defined locations along the wire. The strain recovery during unloading is attributed to reverse twinning, driven by the internal stress generated on loading between the elastic $\gamma$ precipitates and the twinning martensite matrix. The temperature dependence of the twining stress on loading is related to the change in tetragonality of the martensite, as measured by X-ray diffraction.
\end{abstract}

Keywords: $\mathrm{Ni}_{2} \mathrm{MnGa}$, size effect, superelasticity, shape-memory effect, twinning, oligocrystalline materials. 


\section{Introduction}

Ni-Mn-Ga alloys are the most studied of ferromagnetic shape memory alloys because of their large magnetic-field-induced strain (MFIS), which is achieved through the motion of twin boundaries, i.e., twinning by reorientation of martensite variants. The maximum reported MFIS in single crystals is $\sim 6 \%$ [1], $\sim 10 \%$ [2], and $\sim 12 \%$ [3] for five-layered modulated $(5 \mathrm{M})$, seven-layered modulated $(7 \mathrm{M})$ and non-modulated (NM) martensite, respectively. These very large MFIS values, which open potential applications for actuators, sensors and energy harvesters, is attained in single crystals but is near zero in polycrystalline materials because of constraints by grain boundaries on the motion of twin boundaries [4]. Dunand and Müllner proposed that these constraints can be reduced significantly when the grain size becomes comparable to one or more characteristic sample sizes (e.g., film thickness, wire or strut diameter, ribbon width, particle diameter), so that grains become partially surrounded by free space [5]. This approach has been demonstrated in polycrystalline Ni-Mn-Ga fibers [6] and foams [7] for which 1-8.7\% MFIS has been achieved.

Various researchers have recently studied Ni-Mn-Ga microwires. Gómez-Polo et al. [8] prepared wires by rotating water bath melt spinning and observed coexistence of austenite and the 7M and 5M martensites. Zhukova et al. [9-16] prepared glass-coated wires by the Taylor method for Ni-Mn-Ga and Ni-Mn-In/Ni-Co-Mn-In alloys and investigated the effect of the internal stress between the metallic core and the glass sheath on the microstructure, phases and magnetic properties. Qian et al. [17] created superelastic austenitic $\mathrm{Ni}_{49.9} \mathrm{Mn}_{28.6} \mathrm{Ga}_{21.5}$ wires with fine grains by melt extraction; on loading, the plateau stress for stress-induced martensitic transformation increases from 17 to $150 \mathrm{MPa}$ with increasing temperature from 18 to $33{ }^{\circ} \mathrm{C}$, following the Clausius-Clapeyron relationship, with a slope of $8.7 \mathrm{MPa} / \mathrm{K}$. Zhang et al. [18] achieved superelasticity in austenitic $\mathrm{Ni}_{54.0} \mathrm{Mn}_{24.1} \mathrm{Ga}_{21.9}$ wires created by the Taylor method with reversible strains of up to $11.2 \%$ and plateau stress for stress-induced martensitic transformation of $115 \mathrm{MPa}$. Glock et al. [19] studied the effect of annealing on the mechanical and magnetic properties of wire-spun $14 \mathrm{M} \mathrm{Ni-Mn-Ga}$ wires and fabricated fiber composites from these wires. Annealing transformed the microstructure from polycrystalline to oligocrystalline (bamboo grains) and enabled twinning deformation. The composites with annealed fibers exhibited stronger damping than those with as-spun fibers. Liu et al. [20] investigated the effect of Ga substitution by $\mathrm{Fe}$ in melt-extracted $\mathrm{Ni}-\mathrm{Mn}-\mathrm{Ga}(\mathrm{Fe})$ wires on the thermal and magnetic (but not mechanical) properties. Recently, we created Taylor wires with composition of $\mathrm{Ni}_{54.1} \mathrm{Mn}_{26.2} \mathrm{Ga}_{19.7}$ and martensitic bamboo grains, which, under an externally applied tensile stress, exhibit superelastic behavior with twinning stresses of 22-30 $\mathrm{MPa}$ and recoverable tensile strains up to $3.5 \%$, which we speculated to be due to a reversible inter-martensitic transformation [21]. A 1 T magnetic field caused the wire to bend to a surface strain of $1.5 \%$, and during field rotation, the wire deflected back and forth by reversible twinning, an effect called magnetic-torque-induced bending (MTIB). Further investigation of the relative importance of MFIS and MTIB has 
been recently carried out in monocrystalline, martensitic Ni-Mn-Ga beams (with a

square $1 \mathrm{x} 1 \mathrm{~mm}^{2}$ cross section and length varying between 2 and $10 \mathrm{~mm}$ ) subjected to a rotating magnetic field [22].

In the present article, a Ni-Mn-Ga Taylor wire, with $226 \mu \mathrm{m}$ diameter and bamboo grains, is studied during multiple superelastic tensile load-unload cycles. Mechanical testing, metallography and in-situ synchrotron X-ray diffraction reveal that superelasticity is due to reversible martensitic variant reorientation in the bamboo grains containing non-twinning $\gamma$ precipitates, together with lattice rotation.

\section{Experimental procedures}

\subsection{Wire preparation}

$\mathrm{Ni}-\mathrm{Mn}-\mathrm{Ga}$ button ingots with nominal chemical composition $\mathrm{Ni}_{50} \mathrm{Mn}_{28.6} \mathrm{Ga}_{21.4}$ were prepared by induction-melting of high-purity elements. The button ingots were re-melted and cast into $7 \mathrm{~mm}$ diameter rods in copper mold. From these rods, wires with diameters ranging from 90 to $400 \mu \mathrm{m}$ were cast by the Taylor method using a custom-made instrument. The process is described in Ref. [18] and is summarized briefly here. A cast rod is placed in a $8 \mathrm{~mm}$ diameter pyrex tube under Ar cover gas, induction-heated up to melting at $\sim 1150{ }^{\circ} \mathrm{C}$ and drawn in the liquid state within the softened pyrex tube into a thin, pyrex-coated wire under fast solidification conditions provided by natural cooling in ambient air, followed by quenching in sand. One wire was selected, with $226 \mu \mathrm{m}$ diameter. The as-drawn wire with its glass sheath was sealed into a quartz capsule under low vacuum and annealed at $1050{ }^{\circ} \mathrm{C}$ for $1 \mathrm{~h}$ to homogenize and induce grains growth leading to a bamboo-grain structure and aged at $700{ }^{\circ} \mathrm{C}$ for $12 \mathrm{~h}$ to establish $\mathrm{L} 2{ }_{1}$ order. The glass sheath was removed by grinding the wire gently on fine sand paper. The wire was cut into $25 \mathrm{~mm}$ length, and a small segment at its end was cut, metallographically prepared (including etching using Marble's reagent made up of $50 \mathrm{ml} \mathrm{H}_{2} \mathrm{O}, 50 \mathrm{ml} \mathrm{HCl}$ and $10 \mathrm{~g} \mathrm{CuSO}_{4}$ ), and imaged via optical and scanning electron microscope (SEM, Hitachi S-3400N) with its chemical composition obtained by energy dispersive spectroscopy (EDS).

\subsection{Tensile tests}

The wire tensile properties were measured using a dynamical mechanical analyser (DMA, Q800 of TA Instruments). To avoid breaking the wire due to stress concentrations during direct gripping, gripping was performed on tabs consisting of two epoxy/glass composite squares glued onto a piece of cardboard by double-sided adhesive tape. The wire was glued at both its ends to the tabs with epoxy resin, creating a tensile gauge with $15 \mathrm{~mm}$ length. After gripping the wire, the cardboard was cut off by the blade. Tensile deformation was carried out at a displacement rate of $\sim 1 \mu \mathrm{m} / \mathrm{s}$ under deformation control. Strain was measured by cross-head displacement with a high-resolution linear optical encoder with a displacement resolution of $1 \mathrm{~nm}$. 
Load was measured with a resolution of $10^{-4} \mathrm{~N}$ via a load cell.

\subsection{In-situ synchrotron high-energy X-ray diffraction}

Combined tensile testing and in-situ synchrotron high-energy X-ray diffraction was conducted at the 11-ID-C beamline of the Advanced Photon Source (APS) at Argonne National Laboratory (Argonne, IL). A schematic illustration of the experiment is shown in Fig. 1. A custom tensile instrument was used to apply deformation and the load was recorded by a load cell (LCFD-5, Omega) while strain was measured via cross-head displacement. During the tensile test, the cross-head was stopped at 11 loading points (at strains of 0 to 3.33\%) and 6 unloading points (at strains of 0 to $3.33 \%)$. At each applied strain, the monochromatic x-ray beam $\left(1 \times 1 \mathrm{~mm}^{2}\right.$ size and

$0.111650 \AA$ wavelength) was transmitted through the wire and a diffraction pattern was collected with a 2-dimensional (2D) detector. At each applied strain, 15 diffraction patterns were collected to cover the entirety of the $15 \mathrm{~mm}$ gauge by translating the wire in $1 \mathrm{~mm}$ steps. The geometry for the diffraction is described by the coordinates system (Fig. 1): LD corresponds to the loading direction and TD to the transverse direction during the uniaxial tensile test. During collection of diffraction data, the wire was rotated in the range of $\pm 7^{\circ}$ to make more points in the reciprocal lattice tangent with the Ewald sphere, i.e., to collect more diffraction information. The 2D diffraction data were further integrated into $1 \mathrm{D}$ diffraction data (intensity versus $2 \theta$ graphs) by the Fit2D software.

Furthermore, diffraction patterns were collected for one segment at various temperatures, cooling from 177 to $27^{\circ} \mathrm{C}$, using an air convection heating system.

\section{Experimental results}

\subsection{Microstructure and phases}

Fig. 2(a) shows the diameter and the surface condition of the wire after removal of the pyrex coating. Fig. 2(b) shows the fracture surface of the cross section for one small piece obtained by breaking the whole wire at one end after mechanical test, showing cleavage indicative of brittle fracture. Coarse, elongated precipitates, identified as the $\gamma$ phase by diffraction (as described later), are observed after polishing and etching a small section of the wire end, as shown in Fig. 2(c). Martensite plates (labelled M), visible as the fine parallel features in Fig. 2(c), span the whole cross-section, demonstrating that the grain size of the austenitic parent phase is comparable to or larger than the wire diameter, i.e., that a bamboo grain structure is present. Some micro-cavities (micro-holes labelled $\mathrm{H}$ ) are also observed on the surface, which may be related to shrinkage during dendritic solidification. Micrographs of the etched longitudinal cross-sections of a small section of the wire end are shown in Figs. 2(d) and (e). The $\gamma$ precipitates, with a $9 \%$ area fraction, show a growth direction which is nearly perpendicular to the longitudinal direction of the wire, i.e., in the direction of the heat flow when rapid solidification occurred. The precipitates appear mainly at 
one side of the wire, which may have been the nucleation side when the liquid wire solidified after contact with sand just after wire drawing. Figs. 2(d) and (e) also show that most martensite plates form a $\sim 10^{\circ}$ angle with the longitudinal direction of the wire (marked by the dotted line), with other martensite plates perpendicular to it. Similar morphology was reported in magnetron sputtered single crystal Ni-Mn-Ga thin films, where the martensite plates intersect at an angle of $90^{\circ}$ [23]. No grain boundaries is observed in all the longitudinal metallography for the whole piece. The chemical composition was determined with EDS for both phases. Four different measurement areas were selected and the average compositions were $\mathrm{Ni}_{71 \pm 0.9} \mathrm{Mn}_{7 \pm 1.2} \mathrm{Ga}_{22 \pm 0.8}$ for the $\gamma$ phase and $\mathrm{Ni}_{60 \pm 0.8} \mathrm{Mn}_{24 \pm 1.4} \mathrm{Ga}_{16 \pm 1.2}$ for the martensite. Compared to the chemical composition of the ingot, substantial losses of $\mathrm{Mn}$ and $\mathrm{Ga}$ occurred by evaporation during the melting of the ingot.

Two representative diffraction patterns at two different positions along the unstressed wire are shown in Fig. 3 for volumes with and without $\gamma$ phase. The crystal structure for the martensite is identified as non-modulated tetragonal with a=5.39 $\AA, c=6.61 \AA$ (using the face-centered tetragonal (FCT) axis system). We find for the coarse $\gamma$ phase a face-centered cubic structure with $\mathrm{a}=3.86 \AA$, which is larger than $\mathrm{a}=3.618 \AA$ reported previously in $\mathrm{Ni}_{50+x} \mathrm{Mn}_{25} \mathrm{Ga}_{25-\mathrm{x}}$ with $\mathrm{x}>7$ [24], probably because of a chemical composition different than in our wires. The weak peaks correspond to the 200 and 220 reflections of the $\gamma$ phase in Fig. 3(a). A small amount of residual austenite was also detected.

\subsection{Mechanical properties}

All tensile tests were performed on the same wire, which remained unfractured after about 30 cycles. Fig. 4(a) shows load-unload tensile stress-strain curves for maximum applied strains of 3,4 and 5\%. After elastic loading, a long plateau is reached at an applied strain of $\sim 0.8 \%$, which is typical of superelastic behavior such as stress-induced transformation from austenite to martensite in NiTi alloy. When unloading, the stress drops elastically at first before remaining constant at a lower stress plateau. For applied strains of 3 and $4 \%$, the strain is near fully recovered. For a $5 \%$ applied strains, a second elastic range occurs beyond $4 \%$ strain, and a residual strain of $0.4 \%$ is present after unloading. Stress fluctuations occur in both the upper and lower plateaus and are reproducible in each of the three loops. As the wire consists of tetragonal martensite, no stress-induced transformation is expected, and the plateau can be attributed to reorientation of variants, i.e., the motion of the twinning boundary between variants, rather than martensitic or inter-martensitic transformations. To verify that the fluctuations are true and reproducible, 8 cyclic tensile tests up to $2 \%$ strain were performed, as shown in Fig. 4(b) where the curves are shifted on the strain axis to provide better visibility. All 8 stress-strain curves are near identical in the number and magnitude of the stress fluctuations in the two plateaus. As the gripping position for the wire sample is not exactly the same during the two tests shown in Fig. 4(a) and Fig. 4(b), details of fluctuations on the upper 
stress plateau differ slightly.

The effect of temperature on the tensile properties was studied by carrying out tests at various temperatures, heating up from -70 to $55^{\circ} \mathrm{C}$, as shown in Fig. 4(c). On loading, the upper stress plateau (or equivalently the critical stress defined as the maximum stress for the first fluctuation on the plateau) decreases linearly with increasing temperature. On unloading, the stress for the lower plateau increase accordingly. As result, the hysteresis which is associated with energy dissipation during the load-unload cycle, decreases with increasing temperature. The temperature dependence of the critical stress is shown in Fig. 4(d). This temperature dependence of the superelastic hysteresis is opposite to that observed in polycrystalline superelastic $\mathrm{Ni}_{49.9} \mathrm{Mn}_{28.6} \mathrm{Ga}_{21.5}$ wire prepared by melt extraction [15], where the loading plateau stress decreases when decreasing the temperature towards the transformation temperature, indicating the different origin of superelasticity in the present Ni-Mn-Ga wire.

\subsection{In-situ synchrotron X-ray diffraction}

The stress-strain curve recorded during the in-situ X-ray diffraction is shown in Fig. 5. In the $0-0.83 \%$ strain range, only the stress/strain values for the target applied strain were recorded. The red dots on the curve represent the applied strain at which deformation was interrupted and 15 diffraction patterns (labelled 1-15 in Fig. 5) were collected along the full length of the wire. For the first measurement at zero strain, a tensile stress of $\sim 8 \mathrm{MPa}$ was applied to straighten the wire. The maximum applied strain was $\sim 3.3 \%$ and the residual strain upon full unloading was below the detection limit.

Comparing all the diffraction patterns for segments 1-15 over the whole load-unload experiment, variations of patterns occur mostly for segments 7-10, while patterns for the other segments remain mostly unchanged throughout the load-unload loop. Thus, anelastic deformation is mainly located in the center of the wire. Patterns for segment 7-10 before loading, at the maximum applied strain and after unloading are compared in Fig. 6. Laue spots represent the diffraction information of the various martensite variants. Fig. 6 shows that the patterns are the same before loading and after unloading. At the maximum strain, the patterns however show clear changes. For example, when loading from 0 to $3.33 \%$, the partial rings for the $004_{\mathrm{T}}$ and $400_{\mathrm{T}}$ reflections transform into single spots and become less intense (for $004_{\mathrm{T}}$ ) and they return to their original state after unloading from 3.33 to $0 \%$, as marked with a red box for segment 7 in Fig. 6. In the diffraction patterns of segment 8, the intensity variations of the $400_{\mathrm{T}}$ reflections originates from twinning. Thus, segments 7-10 consisted of a large grain containing multi-variants which twin into a near-single variant under the applied strain of $3.33 \%$. The variant remaining at the maximum strain has $004_{\mathrm{T}}$ most closely aligned with the tensile axis which is consistent with $\mathrm{c}>$ a. When the load is removed, the diffraction patterns recover the multi-variant 
features present initially, demonstrating that strain recovery is paralleled by crystallographic reversibility.

The diffraction patterns for segments 7-10 on the upper plateau fluctuations are shown in Fig. 7 for five strains (marked on the stress-strain curve of Fig. 5), including a stress maximum at 1.2 and $3.0 \%$. The colored frames in Fig. 7 highlight the pairs of diffraction patterns showing change, between which variant reorientation (also known as inter-variant transformation) thus occurred. It is apparent that, for each of the four segments, variants reorientation takes place at different applied strain intervals, e.g., $1.2-1.73 \%$ for segment 9 and 3-3.33\% for neighboring segment 10 . This is indicative of a non-uniform deformation process along the wire. The maximum strain of non-modulated martensite with $\mathrm{c} / \mathrm{a}=1.22$ is about $22 \%$ from a single variant state to another single variant state. Starting from a mixed variant state, the maximum strain is about $11 \%$ for a two-variant state. Deformation occurs in about $27 \%$ of the length (4 segments of 15) corresponding to a net strain of about $3 \%$ which agrees with the superelastic portion of the total strain which is $3 \%$.

To investigate the relationship between the lattice parameters and the twinning stress, $1 \mathrm{D}$ diffraction curves created by integrating the 2D diffraction pattern are fitted by the Lebail method using the EXPGUI software package [25] and the unit-cell lattice parameters, a and c, are determined (as reported earlier, a=5.39 $\AA, c=6.61 \AA$ at ambient temperature). The results for an experiment performed by cooling from 177 to $27^{\circ} \mathrm{C}$ are reported in Fig. 8 showing the lattice parameter thermal strains, $\Delta \mathrm{a} / \mathrm{a}$ and $\Delta \mathrm{c} / \mathrm{c}$. It is apparent from this figure that the unit cell undergoes anisotropic thermal changes as the value of a decreases while that of $c$ increases during cooling. Correspondingly, the tetragonality, defined by the ratio c/a, increases with decreasing temperature, as shown in Fig. 9(b). This figure also shows the volumetric thermal strain, defined as $\Delta \mathrm{V} / \mathrm{V}$ (where the unit cell volume is $\mathrm{V}=\mathrm{a}^{2} \mathrm{c}$ ), corresponding to a volumetric contraction during cooling with a coefficient of $60 \times 10^{-6} \mathrm{~K}^{-1}$ averaged between 177 and $27^{\circ} \mathrm{C}$.

\section{Discussion}

\subsection{Structure evolution during tensile deformation}

Based on the Bain model, the tetragonal unit cell for martensite can be described as a distortion of the $\mathrm{L} 2{ }_{1}$ austenitic parent phase, i.e., one axis is stretched and the other two are shrunk. The diffraction patterns cover the diffraction information of three domains, each of which consists of a pair of variants in twinning relationship, shown in Fig. 9(a); they are marked by $(\mathrm{M}+, \mathrm{T} 1)(\mathrm{M}-, \mathrm{T} 2)$ and $\left(\mathrm{V} 1, \mathrm{~T}_{\mathrm{V} 1}\right)$ [26-28], where $\mathrm{M}, \mathrm{T}$ and $\mathrm{V}$ represent the variants with $\mathrm{c}$ axis pointing towards the LD, TD and beam directions, respectively. The + subscript denotes the counterclockwise rotation direction related to the intermediate position between $\mathrm{M}+$ and $\mathrm{M}-$. As the diffraction information, i.e., Laue spot, of the variant oriented in twinning relationship with V1 is 
not detected, it is denoted by $\mathrm{T}_{\mathrm{V} 1}$. By measuring the angles directly on the diffraction pattern on Fig. 9(a), the misorientation angle between $\mathrm{M}+$ and $\mathrm{M}$ - is determined to be $\varphi=\sim 13^{\circ}$ and that between $\mathrm{T} 1$ and $\mathrm{T} 2$ to be $\psi=\sim 8^{\circ}$, which is in reasonable agreement with the equation:

$$
\varphi / 2+\psi / 2=2 \arctan (\mathrm{c} / \mathrm{a})-90^{\circ}
$$

as $\arctan (\mathrm{c} / \mathrm{a})$ is equal to $\sim 50.9^{\circ}$, using values for $\mathrm{c}$ and a reported earlier.

During straining, as shown in the pattern on the right of Fig. 9(a), the variants reorient, i.e., twinning occurs by the motion of the twin boundary between variants. As a result, the favorably orientated $\mathrm{M}+$ and $\mathrm{M}-$, variants grow at the expense of the T1 and T2 variants, respectively, corresponding to the intensity of the 004 peak in red circles decreasing while that of 400 peak increases in the transverse direction [29]. Simultaneously, a rigid lattice rotation occurs as measured by the reduction of the misorientation angle $\varphi$ between $\mathrm{M}+$ and $\mathrm{M}$ - from $13^{\circ}$ to $\sim 0^{\circ}$ and increase of $\psi$ between $\mathrm{T} 1$ and $\mathrm{T} 2$ from $8^{\circ}$ to $21^{\circ}$. A schematic illustration describing the process at the atomic scale is shown in Fig. 9(b).

\subsection{Mechanism for fluctuations and superelasticity}

The conventional superelastic effect in shape memory alloys utilizes a stress-induced martensitic phase transformation which provides a chemical driving force for recovering the original shape upon unloading. In the present experiments, there is no phase transformation and, thus, there is no chemical driving force. We believe that the driving force for recovery is provided by internal stress fields in a mechanism similar to the two-way shape memory effect (TWSME) in other shape-memory alloys. There are several methods to promote TWSME which all utilize internal stress fields generated by (i) severe plastic deformation below the martensite start temperature [30], (ii) thermomechanical cycling [31], (iii) stress-assisted aging [32], and (iv) indentation [33]. The TWSME utilizes the martensitic transformation which requires large stresses. In contrast, superelasticity observed here utilizes twinning which operates at very low stresses in Ni-Mn-Ga.

The reorientation process, which is controlled by the twinning dislocation moving on successive twin planes (i.e., the movement of twin boundaries), takes place only when the external load approaches the twinning stress. The twinning stress for non-modulated Ni-Mn-Ga is typically in the order of 10 to $20 \mathrm{MPa}$ [34]. Probably because of the $\gamma$ precipitates and the nickel-rich concentration of the wire, the observed plateau stress, $\sim 50 \mathrm{MPa}$, is somewhat high $[1-2,35]$. Once twin boundaries become mobile and start to propagate, the internal stress is reduced and less energy is required for their further propagations. Thus, each of the stress peaks on the plateau corresponds to the maximum stress required to initiate local twinning. This process takes place successively at localized volumes in the wire (see Fig. 7), resulting in 
stress fluctuations on the upper stress plateau when measured over the whole wire length. The reproducibility of the stress variations for eight cycles (see Fig. 4(b)) can be attributed to reorientation process taking place in various segments following a fixed sequence, probably reflecting different crystallographic orientations (and thus critical resolved stress to induce twinning) with respect to the applied stress.

As reviewed earlier, Qian et al. [17] and Zhang et al. [18] reported superelasticity in austenitic Ni-Mn-Ga wires by stress-induced martensitic-austenitic transformations on loading and unloading, and we reported superelastic behavior in Ni-Mn-Ga wires by reversible inter-martensitic transformation [21]. By contrast, in the present work, we show that superelasticity is due to reversible martensitic variant reorientation without crystallographic transformation, albeit in a Ni-Mn-Ga wire which is richer in nickel than those in the above cited studies. Generally, the twinning process or variants reorientation observed in $\mathrm{Ni}-\mathrm{Mn}-\mathrm{Ga}$ is expected to be irreversible on unloading, thus creating a permanent plastic deformation mechanism. Thus, we believe that the reversible twinning on (un)loading in our wires is due to internal stresses generated by the motion of twin boundaries in the presence of non-twinning obstacles, i.e., the $\gamma$ precipitates. Elastic stress is stored in the precipitates during the multi-variants transforming into single one. Thus, the release of this internal stress can drive the single variant to transform back into the initial state prior to applying stress, i.e., re-creating multi-variants upon mechanical unloading. A similar hypothesis was advanced to explain the $\sim 4 \%$ recovery observed in a $5 \mathrm{M} \mathrm{Ni-Mn-Ga} \mathrm{single} \mathrm{crystal,}$ where obstacles to the twins were attributed the rough surface of the sample [36]. Thus, the superelastic behavior of the present wires can be attributed to the existence of the $\gamma$ precipitates (and possibly also surface roughness). For NiTi alloy undergoing stress-insisted aging, nano-scale $\mathrm{Ni}_{4} \mathrm{Ti}_{3}$ precipitates are dispersed uniformly in the martensite matrix. However, no reverse process was observed on unloading, corresponding to the fact that the transition from multi-variants into one single variant is irreversible for this alloy [37]. Therefore, it is the size or shape, and volume fraction of the precipitates that determines whether the precipitates can store elastic stress during multi-variants transforming into one single variant on loading and subsequently drive the reverse process on unloading. As Fig. 2 shows, the gamma precipitates are plate-like and span almost across the entire wire. Almost all martensite plates terminate at a $\gamma$ precipitate. Thus, these precipitates effectively create elastic incompatibility stresses during twinning on loading, which are relaxed on unloading by reversible twinning, leading to full strain recovery and a reproducible sequence of twinning events on subsequent load-unload loops, thus explaining the reproducible shape of the superelastic plateaus. This effect is analogous to the large twinning-induced recovery reported by Straka et al. [38]. Twinning dislocations were piling up on plates of conjugate twins. The pile-up stresses provided the restoring force for a pseudo-elastic global recovery of $0.3 \%$. Since only a small volume fraction contributed to recovery in their sample, the local recovery can be estimated to several percents, comparable to the superelastic strains reported here. 


\subsection{Effect of temperature on tensile behavior}

It has been shown in Fig. 4 that the twinning stress decreases with increasing temperature. Also, the lattice parameters change monotonously, as does the twinning stress, when decreasing temperature, as shown in Fig. 8. We hypothesize that the temperature dependence of the twinning stress is linked to the anisotropic thermal expansion and the increase of tetragonality. The Burgers vector of twinning dislocations increases with increasing tetragonality [26, 39], which increases the Peierls stress and, thus, the twinning stress. Similar results have been reported for monocrystalline $5 \mathrm{M}$ modulated martensite for which the twinning stress increases approximately linearly with decreasing temperature for Type I twins [40-41]. Finally, the reason for the discontinuity at $47^{\circ} \mathrm{C}$ for the temperature dependence of $\Delta \mathrm{a} / \mathrm{a}$ and $\Delta \mathrm{c} / \mathrm{c}$ remains unknown and thus needs further study.

\section{Conclusions}

A Ni-Mn-Ga microwire was prepared by the Taylor method, consisting of bamboo grains with a tetragonal martensite matrix and coarse $\gamma$ phase precipitates. The wire exhibits superelastic behavior with reproducible fluctuations on the upper stress plateau during uniaxial tensile tests at ambient temperature. In-situ synchrotron $\mathrm{X}$-ray diffraction experiments reveal that superelasticity is due to reversible variants reorientation (i.e., (de)twinning), with lattice rotation, occurring consecutively in well-defined segments of the wire during loading and unloading, which results in reproducible fluctuations in the stress plateau. The superelastic strain recovery during unloading is attributed to the internal stresses created, during loading, by the twinning martensite in the presence of the non-twinning precipitates. The plateau stress increases with decreasing temperature from 55 to $-70{ }^{\circ} \mathrm{C}$ and this temperature dependence is related to the change of unit cell tetragonality with temperature, as measured by X-ray diffraction.

\section{Acknowledgments}

This research was supported by the US National Science Foundation through Grant No. DMR-1207282 at Northwestern University (Z.L.W. and D.C.D.), the National Basic Research Program of China (973 Program) under Contract No. 2012CB619405 (Z.H.N. and Y.D.W.) at Beijing Institute of Technology, and Grant No. DMR-1207192 at Boise State University (P.M.). Y.D.W acknowledges support from the Fundamental Research Funds for the Central Universities (Grant No. 06111020), and the fundamental research fund by State Key Laboratory for Advanced Metals and Materials (Grant No. 2014Z-01). Z.L.W. also acknowledges support from the Chinese Scholarship Council (CSC). Use of the Advanced Photon Source was supported by the U.S. Department of Energy, Office of Science, Office of Basic Energy Science, under Contract No. DE-AC02-06CH11357. We thank Dr. Cun Yu at China University of Petroleum for assistance during experiments at APS, Ms. Nikki Kucza at Boise 
State University for preparing the alloy ingot, and Prof. L.C. Brinson at Northwestern University for use of her dynamical mechanical analysis instrument. 


\section{References}

[1] S.J. Murray, M. Marioni, S.M. Allen, R.C. O'Handley, T.A. Lograsso, 6\% magnetic-field-induced strain by twin-boundary motion in ferromagnetic Ni-Mn-Ga, Appl. Phys. Lett. 77 (2000) 886-888.

[2] A. Sozinov, A.A. Likhachev, N. Lanska, K. Ullakko, Giant magnetic-field-induced strain in NiMnGa seven-layered martensitic phase, Appl. Phys. Lett. 80 (2002) 1746-1748.

[3] A. Sozinov, N. Lanska, A. Soroka, W. Zou, 12\% magnetic field-induced strain in Ni-Mn-Ga-based non-modulated martensite, Appl. Phys. Lett. 102 (2013) 021902-5.

[4] U. Gaitzsch, M. Pötschke, S. Roth, B. Rellinghaus, L. Schultz, A $1 \%$ magnetostrain in polycrystalline 5M Ni-Mn-Ga, Acta Mater. 57 (2009) 365-370.

[5] D.C. Dunand, P. Müllner, Size Effects on Magnetic Actuation in Ni-Mn-Ga Shape-Memory Alloys, Adv. Mater. 23 (2011) 216-232.

[6] N. Scheerbaum, O. Heczko, J. Liu, D. Hinz, L. Schultz, O. Gutfleisch, Magnetic field-induced twin boundary motion in polycrystalline Ni-Mn-Ga fibres, New J. Phys. 10 (2008) 073002.

[7] M. Chmielus, X.X. Zhang, C. Witherspoon, D.C. Dunand, P. Müllner, Giant magnetic-field-induced strains in polycrystalline Ni-Mn-Ga foams, Nature Mater. 8 (2009) 863-866.

[8] C. Gomez-Polo, J.I. Perez-Landazabal, V. Recarte, V. Sanchez-Alarcos, G. Badini-Confalonieri, M. Vazquez, Ni-Mn-Ga ferromagnetic shape memory wires, J. Appl. Phys. 107 (2010) 123908-7.

[9] V. Zhukova, V. Rodionova, L. Fetisov, A. Grunin, A. Goikhman, A. Torcunov, A. Aronin, G. Abrosimova, A. Kiselev, N. Perov, Magnetic properties of Heusler-type microwires and thin films, IEEE Trans. Magn. 50 (2014) 2505504.

[10] A. Zhukov, V. Rodionova, M. Ilyn, A.M. Aliev, R. Varga, S. Michalik, A. Aronin, G. Abrosimova, A. Kiselev, M. Ipatov, V. Zhukova, Magnetic properties and magnetocaloric effect in Heusler-type glass-coated NiMnGa microwires, J. Alloys Compd. 575 (2013) 73-79.

[11] V. Rodionova, M. Ilyn, A. Granovsky, N. Perov, V. Zhukova, G. Abrosimova, A. Aronin, A. Kiselev, A. Zhukov, Internal stress induced texture in Ni-Mn-Ga based glass-covered microwires, J. Appl. Phys. 114 (2013) 123914.

[12] A.S. Aronin, G.E. Abrosimova, A.P. Kiselev, V. Zhukova, R. Varga, A. Zhukov, The effect of mechanical stress on $\mathrm{Ni}_{63.8} \mathrm{Mn}_{11.1} \mathrm{Ga}_{25.1}$ microwire crystalline structure and properties, Intermetallics 43 (2013) 60-64.

[13] A. Zhukov, C. Garcia, M. Ilyn, R. Varga, J.J. del Val, A. Granovsky, V. Rodionova, M. Ipatov, V. Zhukova, Magnetic and transport properties of granular and Heusler-type glass-coated microwires, J. Magn. Magn. Mater. 324 (2012) 3558-3562.

[14] R. Varga, T. Ryba, Z. Vargova, K. Saksl, V. Zhukova, A. Zhukov, Magnetic and structural properties of Ni-Mn-Ga Heusler-type microwires, Scripta Mater. 65 (2011) 703-706.

[15] V. Zhukova, M. Ipatov, A. Granovsky, A. Zhukov, Magnetic properties of Ni-Mn-In-Co Heusler-type glass-coated microwires, J. Appl. Phys. 115 (2014) 
17A939.

[16] V. Zhukova, V. Chernenko, M. Ipatov, A. Zhukov, Magnetic properties of Heusler-type NiMnGa glass-coated microwires, IEEE Trans. Magn. PP (2015) 1-1.

[17] M.F. Qian, X.X. Zhang, C. Witherspoon, J.F. Sun, P. Müllner, Superelasticity and shape memory effects in polycrystalline Ni-Mn-Ga microwires, J. Alloys Compd. 577, Supplement 1 (2013) 296-299.

[18] Y. Zhang, M. Li, Y.D. Wang, J.P. Lin, K.A. Dahmen, Z.L. Wang, P.K. Liaw, Superelasticity and serration behavior in small-sized NiMnGa alloys, Adv. Eng. Mater. 16 (2014) 955-960.

[19] S. Glock, X.X. Zhang, N.J. Kucza, P. Müllner, V. Michaud, Structural, physical and damping properties of melt-spun $\mathrm{Ni}-\mathrm{Mn}-\mathrm{Ga}$ wire-epoxy composites, Compos. Part A: Appl. S. 63 (2014) 68-75.

[20] Y. Liu, X. Zhang, D. Xing, H. Shen, D. Chen, J. Liu, J. Sun, Martensite transformation and magnetic properties of Ni50Mn25Ga25-xFex ferromagnetic microwires for application in microdevices, Phys. Status Solidi A 212 (2015) 855-861. [21] P. Zheng, N.J. Kucza, C.L. Patrick, P. Müllner, D.C. Dunand, Mechanical and magnetic behavior of oligocrystalline Ni-Mn-Ga microwires, J. Alloys Compd. 624 (2015) 226-233.

[22] N.J. Kucza, C.L. Patrick, P. Müllner, D.C. Dunand, Magnetic-field-induced bending and straining of Ni-Mn-Ga single crystal beams with high aspect ratios Submitted for publication (2015).

[23] G.J. Mahnke, M. Seibt, S.G. Mayr, Microstructure and twinning in epitaxial NiMnGa films, Phys. Rev. B 78 (2008) 012101.

[24] Y. Ma, C. Jiang, Y. Li, H. Xu, C. Wang, X. Liu, Study of $\mathrm{Ni}_{50+\mathrm{x}} \mathrm{Mn}_{25} \mathrm{Ga}_{25-\mathrm{x}}$ $(\mathrm{x}=2-11)$ as high-temperature shape-memory alloys, Acta Mater. 55 (2007) $1533-1541$.

[25] B.H. Toby, EXPGUI, a graphical user interface for GSAS, J. Appl. Crystallogr. 34 (2001) 210-213.

[26] R.C. Pond, B. Muntifering, P. Müllner, Deformation twinning in $\mathrm{Ni}_{2} \mathrm{MnGa}$, Acta Mater. 60 (2012) 3976-3984.

[27] N. Zárubová, Y. Ge, O. Heczko, S.P. Hannula, In situ TEM study of deformation twinning in Ni-Mn-Ga non-modulated martensite, Acta Mater. 61 (2013) 5290-5299.

[28] B. Muntifering, R.C. Pond, L. Kovarik, N.D. Browning, P. Müllner, Intra-variant substructure in Ni-Mn-Ga martensite: Conjugation boundaries, Acta Mater. 71 (2014) $255-263$.

[29] Z.H. Nie, Y. Ren, T. Terai, Y.D. Wang, D.E. Brown, T. Kakeshita, Evidence for preferential rearrangements of martensite variants by magnetic field in antiferromagnetic CoO crystal, Appl. Phys. Lett. 95 (2009) 051914-3.

[30] I. Karaman, B. Kockar, J.I. Kim, Y. Chumlyakov, A method to enhance cyclic reversibility of NiTiHf high temperature shape memory alloys, Scripta Mater. 54 (2006) 2203-2208.

[31] R. Stalmans, J. Vanhumbeeck, L. Delaey, Thermomechanical cycling, 2 way memory and concomitant effects in Cu-Zn-Al alloys, Acta Metall. Mater. 40 (1992) $501-511$. 
[32] T. Fukuda, A. Deguchi, T. Kakeshita, T. Saburi, Two-way shape memory properties of a Ni-rich Ti-Ni alloy aged under tensile-stress, Mater. T. JIM 38 (1997).

[33] E. Qin, N.J. Peter, M. Frensemeier, C.P. Frick, E. Arzt, A.S. Schneider, Vickers indentation induced one-way and two-way shape memory effect in austenitic NiTi, Adv. Eng. Mater. 16 (2014) 72-79.

[34] K. Rolfs, M. Chmielus, J.M. Guldbakke, R.C. Wimpory, A. Raatz, W. Petry, P. Müllner, R. Schneider, Key properties of Ni-Mn-Ga based single crystals grown with the SLARE technique, Adv. Eng. Mater. 14 (2012) 614-635.

[35] L. Straka, O. Heczko, H. Seiner, N. Lanska, J. Drahokoupil, A. Soroka, S. Fähler, H. Hänninen, A. Sozinov, Highly mobile twinned interface in $10 \mathrm{M}$ modulated Ni-Mn-Ga martensite: Analysis beyond the tetragonal approximation of lattice, Acta Mater. 59 (2011) 7450-7463.

[36] M. Chmielus, C. Witherspoon, K. Ullakko, P. Müllner, R. Schneider, Effects of surface damage on twinning stress and the stability of twin microstructures of magnetic shape memory alloys, Acta Mater. 59 (2011) 2948-2956.

[37] D.Y. Cong, G. Saha, M.R. Barnett, Thermomechanical properties of Ni-Ti shape memory wires containing nanoscale precipitates induced by stress-assisted ageing, Acta Biomater. 10 (2014) 5178-5192.

[38] L. Straka, H. Hänninenn, N. Lanska, A. Sozinov, Twin interaction and large magnetoelasticity in Ni-Mn-Ga single crystals, J. Appl. Phys. 109 (2011) 063504-7.

[39] P. Müllner, W.M. Kriven, On the role of deformation twinning in domain reorganization and grain reorientation in ferroelastic crystals, J Mater. Res. 12 (1997) 1771-1776.

[40] N. Glavatska, G. Mogylny, I. Glavatskiy, V. Gavriljuk, Temperature stability of martensite and magnetic field induced strain in Ni-Mn-Ga, Scripta Mater. 46 (2002) 605-610.

[41] L. Straka, A. Soroka, H. Seiner, H. Hänninen, A. Sozinov, Temperature dependence of twinning stress of Type I and Type II twins in 10M modulated Ni-Mn-Ga martensite, Scripta Mater. 67 (2012) 25-28.

Figure Captions

Fig.1 Schematic illustration of setup for in-situ X-ray diffraction experiment.

Fig. 2 SEM micrographs of (a) wire, (b) fracture surface and (c-e) optical micrographs of (c) radial and (d-e) longitudinal cross-sections, showing martensite (M) plates, precipitates $(\gamma)$ and surface cavities $(\mathrm{H})$. The dotted lines correspond to the direction of the martensite plates.

Fig. 3 Diffraction patterns for segments 3 and 10, with and without $\gamma$ phase detected. The subscripts of $\mathrm{P}, \gamma$ and $\mathrm{T}$ denote parent (austenitic) phase, $\gamma$ phase and tetragonal martensite. 
Fig. 4 Tensile stress-strain curves for (a) three maximum applied strain values 3, 4, and 5\% at ambient temperature, (b) eight loading-unloading cycles with a constant maximum applied strain of $2 \%$ at ambient temperature (curves are shifted along the strain axis), (c) thirteen loading-unloading cycles with a constant maximum applied strain of $2 \%$ at various temperatures (curves are shifted along the strain axis), and (d) dependence of twinning stress from (c) on the temperature over the range of -70 to $55{ }^{\circ} \mathrm{C}$. The curves are shifted along strain axis to facilitate comparisons in (b) and (c).

Fig. 5 Tensile stress-strain curve recorded during in-situ x-ray experiments (no continuous load data on loading from 0 to $0.83 \%$ ). The red squares correspond to the strain values where diffraction patterns were collected on fifteen segments (marked $1-15$ on the wire schematic on the left) covering the whole gauge length of the wire.

Fig. 6 Diffraction patterns for segments 7-10 before loading, at the maximum applied strain and after unloading.

Fig. 7 Diffractions pattern for segments 7-10 at different applied loading strains with change in patterns highlighted with colored boxes.

Fig. 8 Temperature dependence during cooling from 177 to $27{ }^{\circ} \mathrm{C}$ of (a) lattice parameter thermal strain of tetragonal unit cell (b) volumetric strain and tetragonality of unit cell.

Fig. 9 (a) Diffraction patterns indexed with three kinds of variants before loading (left) and at the maximum applied strain (right). (b) Schematic for the lattice rotation and variants reorientation at the atomic scale. 


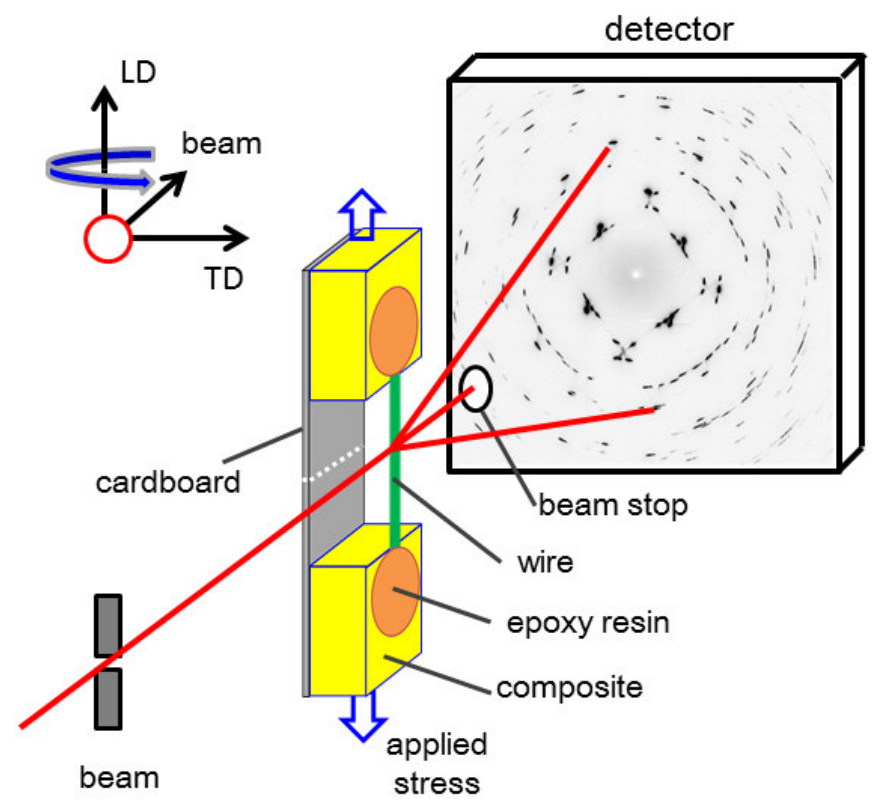

Fig.1 Schematic illustration of setup for in-situ X-ray diffraction experiments 

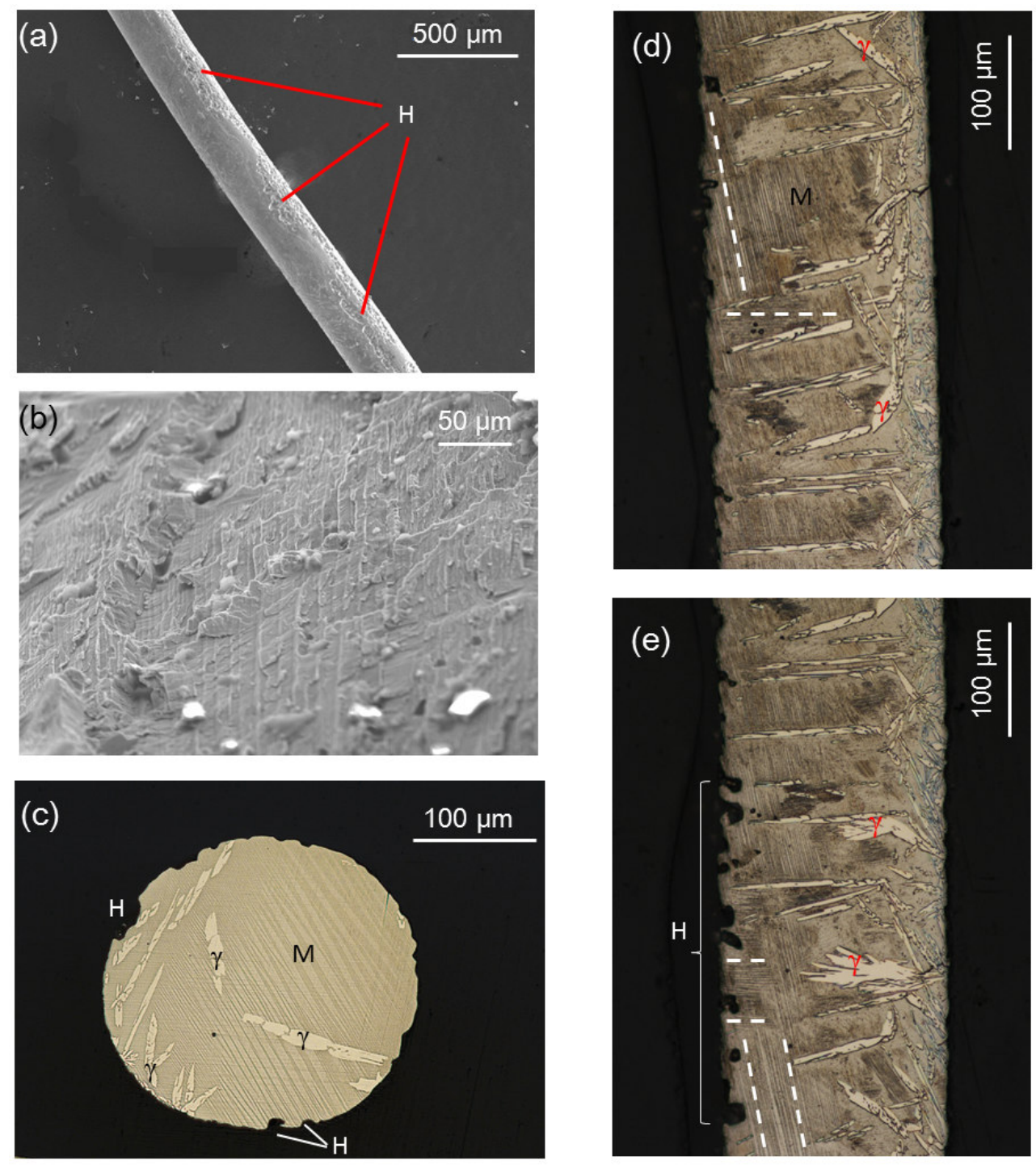

Fig. 2 SEM micrographs of (a) wire, (b) fracture surface and (c-e) optical micrographs of (c) radial and (d-e) longitudinal cross-sections, showing martensite (M) plates, precipitates $(\gamma)$ and surface cavity $(\mathrm{H})$. The dotted lines correspond to the direction of the martensite plates. 

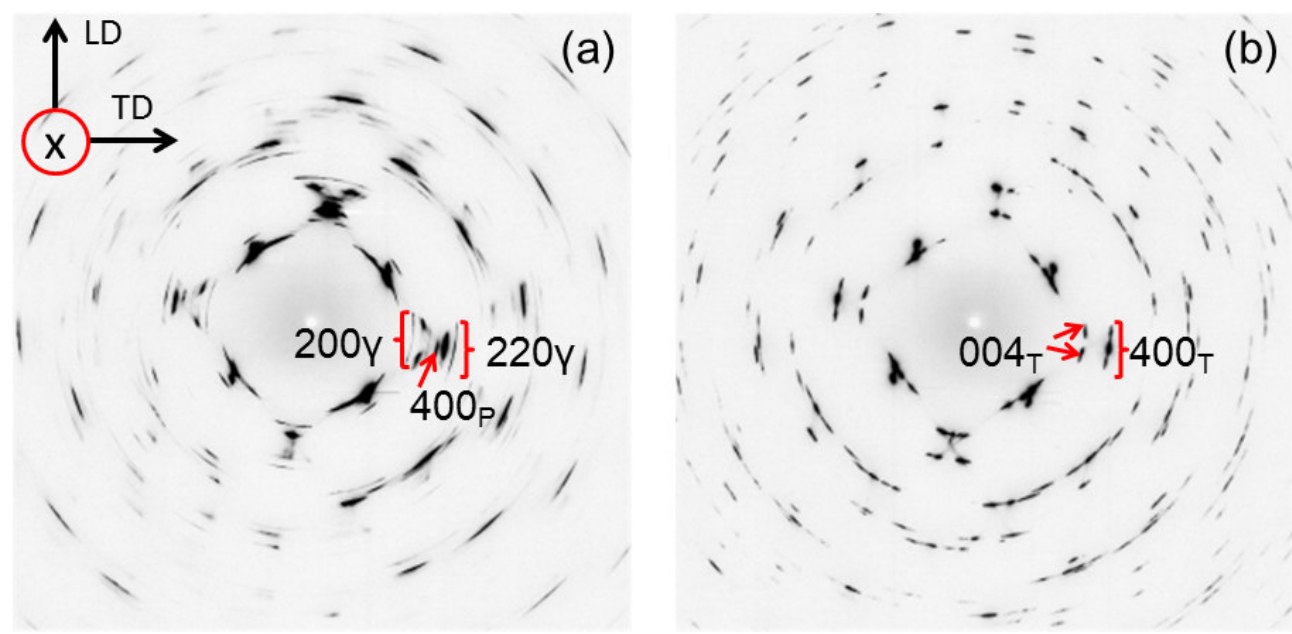

Fig. 3 Diffraction patterns for segments 3 and 10, with and without $\gamma$ phase detected. The subscripts of $\mathrm{P}, \gamma$ and $\mathrm{T}$ denote parent phase, $\gamma$ phase and tetragonal martensite.
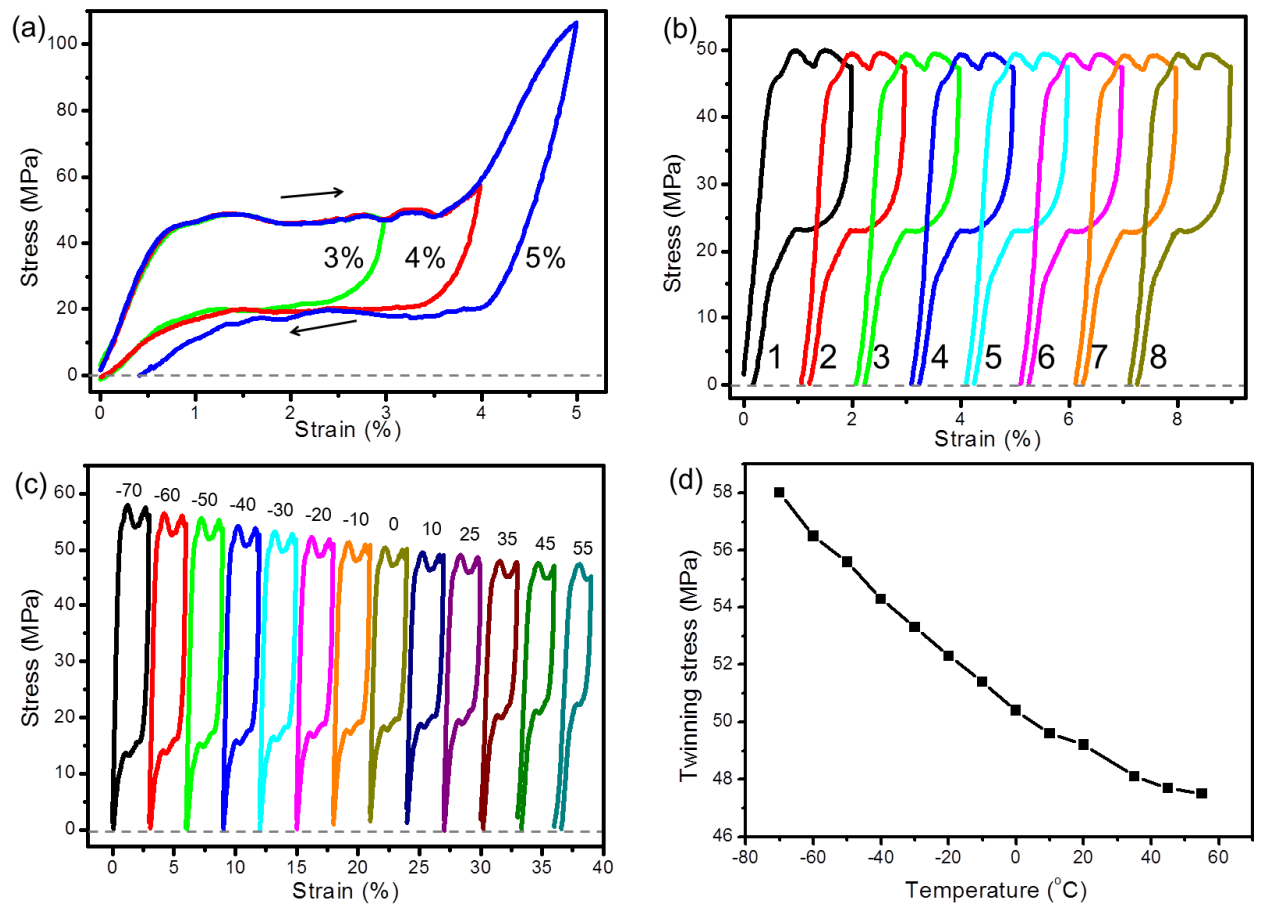

Fig. 4 Tensile stress-strain curves for (a) three maximum applied strain values 3, 4, and $5 \%$ at ambient temperature, (b) eight loading-unloading cycles with a constant maximum applied strain of $2 \%$ at ambient temperature (curves are shifted along the strain axis), (c) thirteen loading-unloading cycles with a constant maximum applied strain of $2 \%$ at various temperatures (curves are shifted along the strain axis), and (d) dependence of twinning stress from (c) on the temperature over the range of -70 to $55{ }^{\circ} \mathrm{C}$. The curves are shifted along strain axis to facilitate comparisons in (b) and (c). 


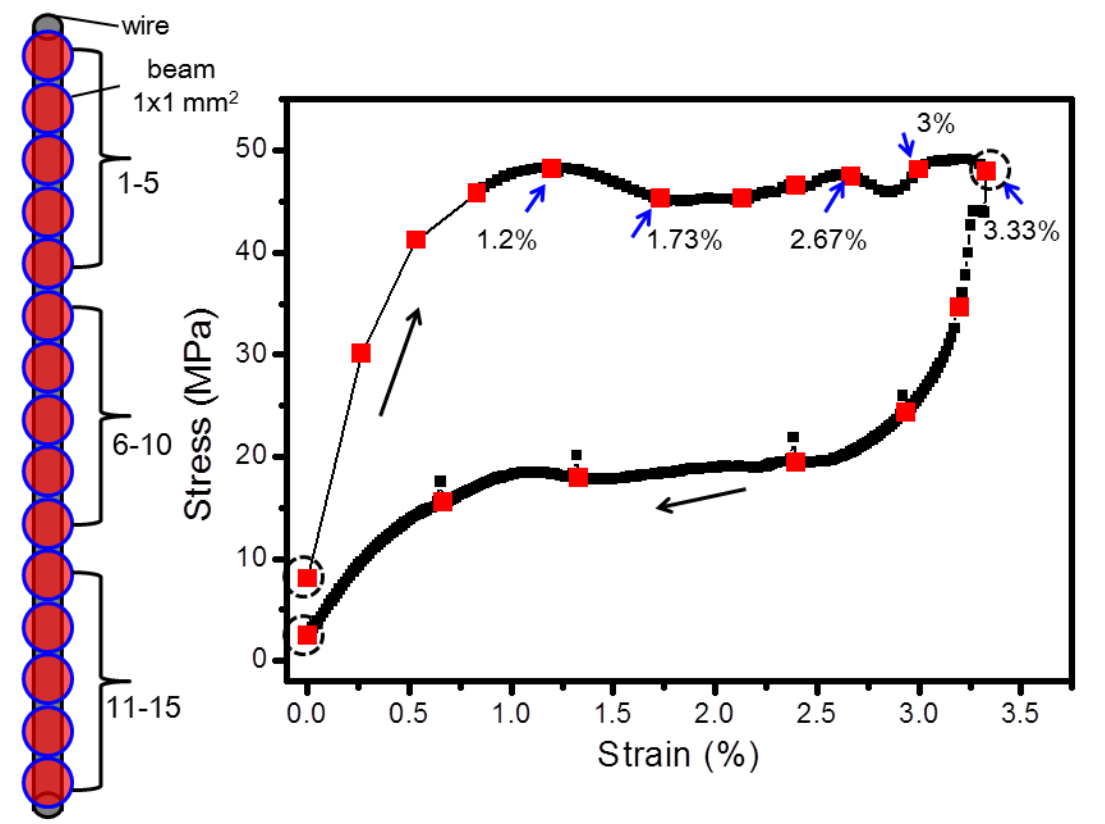

Fig. 5 Tensile stress-strain curve recorded during in-situ x-ray experiments (no continuous load data on loading from 0 to $0.83 \%$ ). The red squares correspond to the strain values where diffraction patterns were collected. Fifteen segments (marked 1-15 on the wire schematic on the left) covering the whole gauge length of the wire.

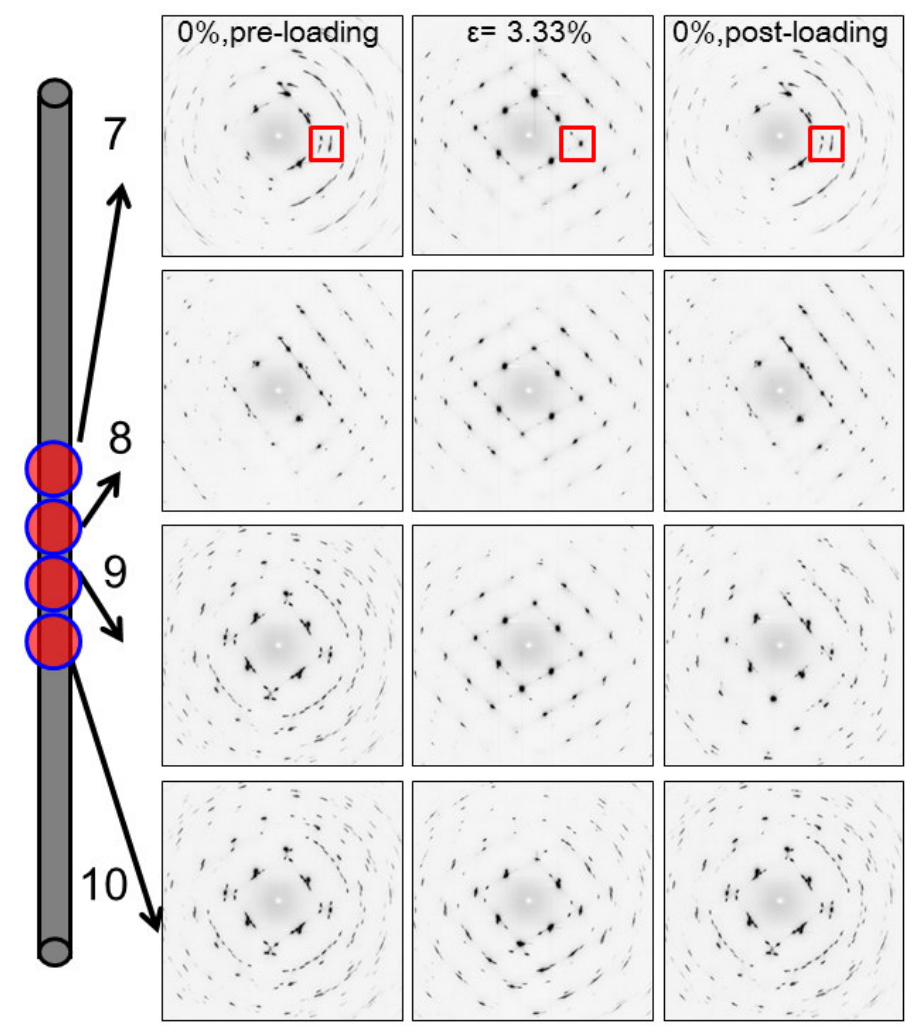

Fig. 6 Diffraction patterns for spot 7-10 before loading, at the maximum applied strain and after unloading. 


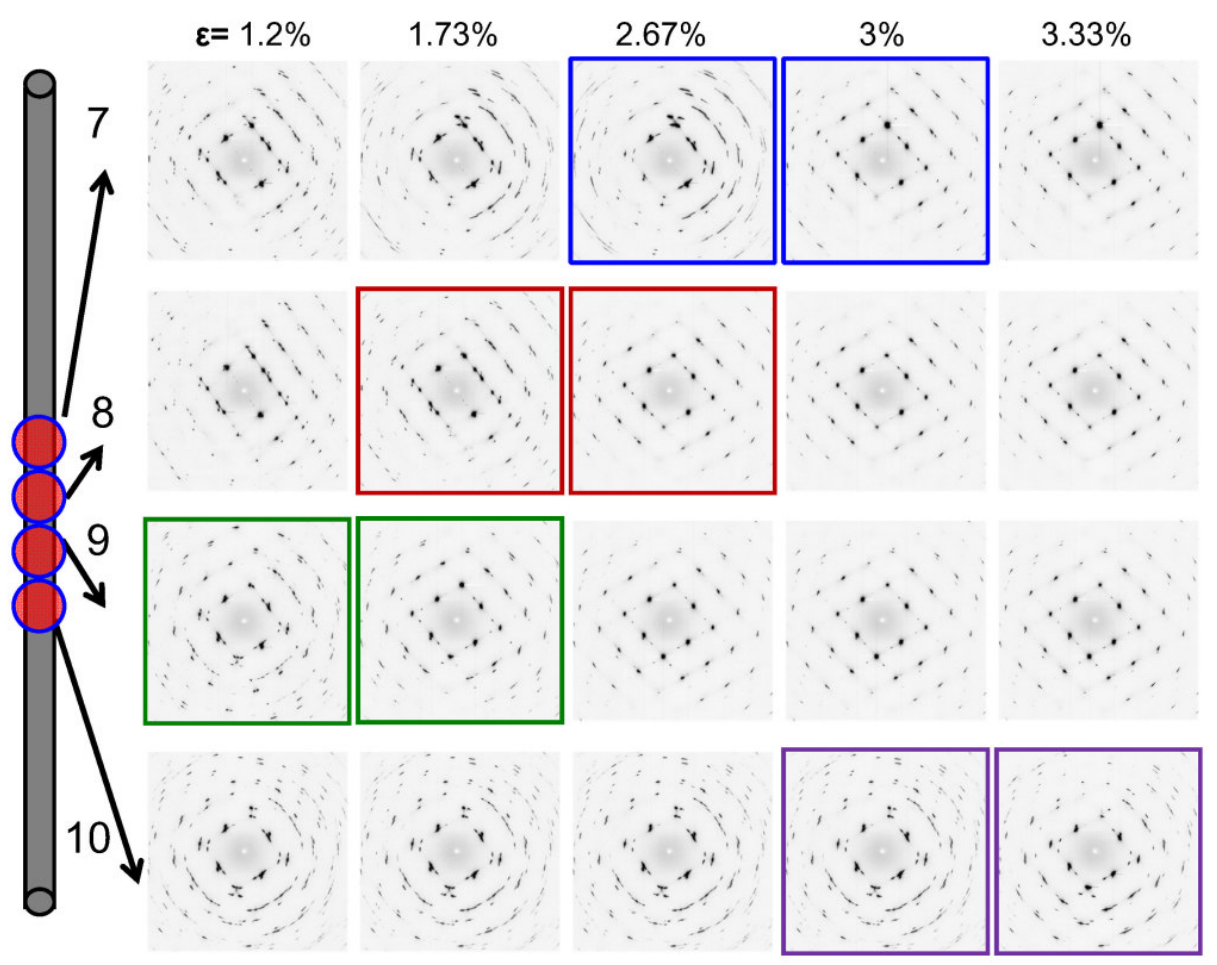

Fig. 7 Diffractions pattern for segments 7-10 at different applied loading strains with change in patterns highlighted with colored boxes. 

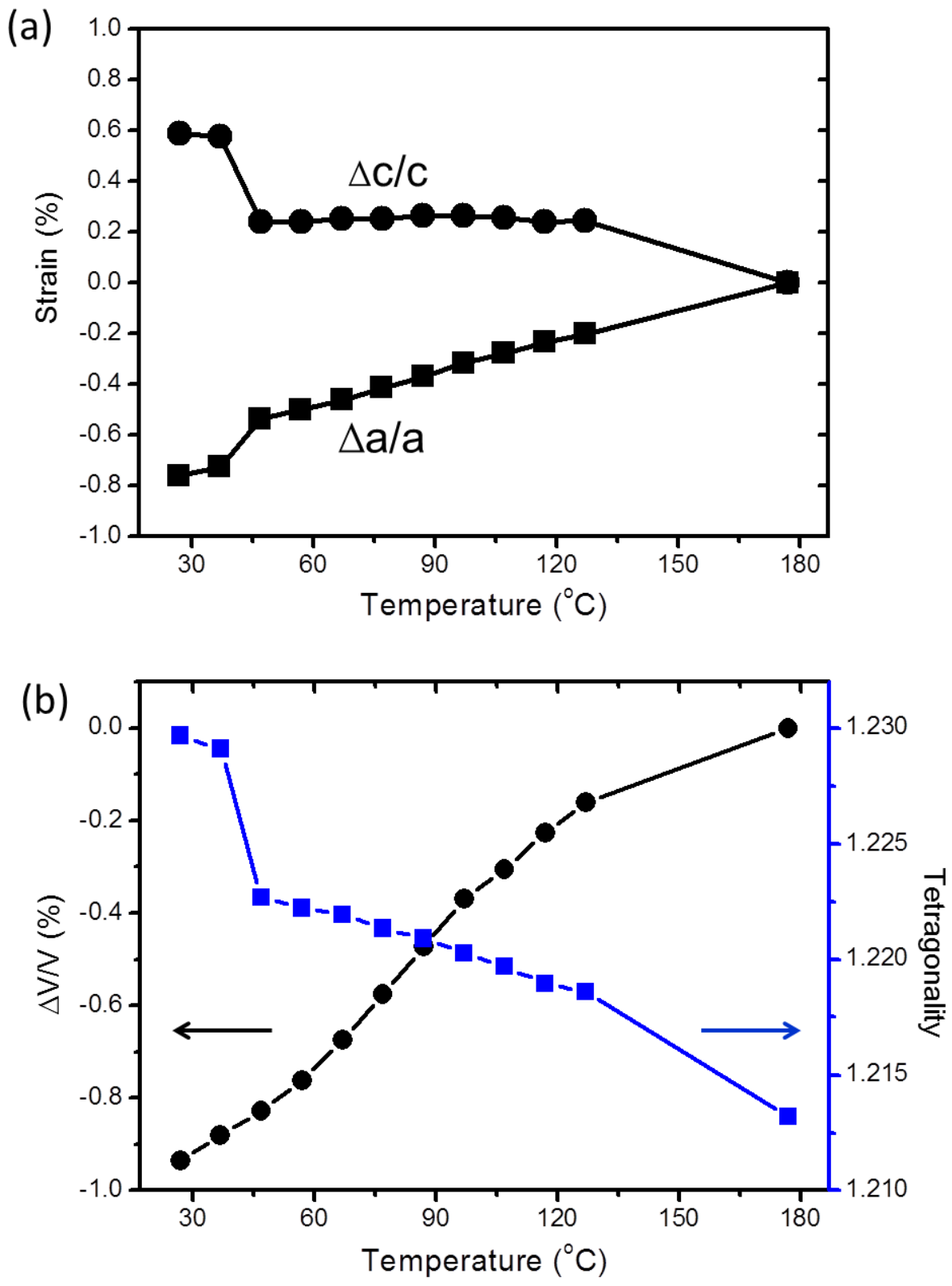

Fig. 8 (a) Temperature dependence during cooling from 177 to $27^{\circ} \mathrm{C}$ of (a) lattice parameter thermal strain of tetragonal unit cell (b) volumetric strain and tetragonality of unit cell. 

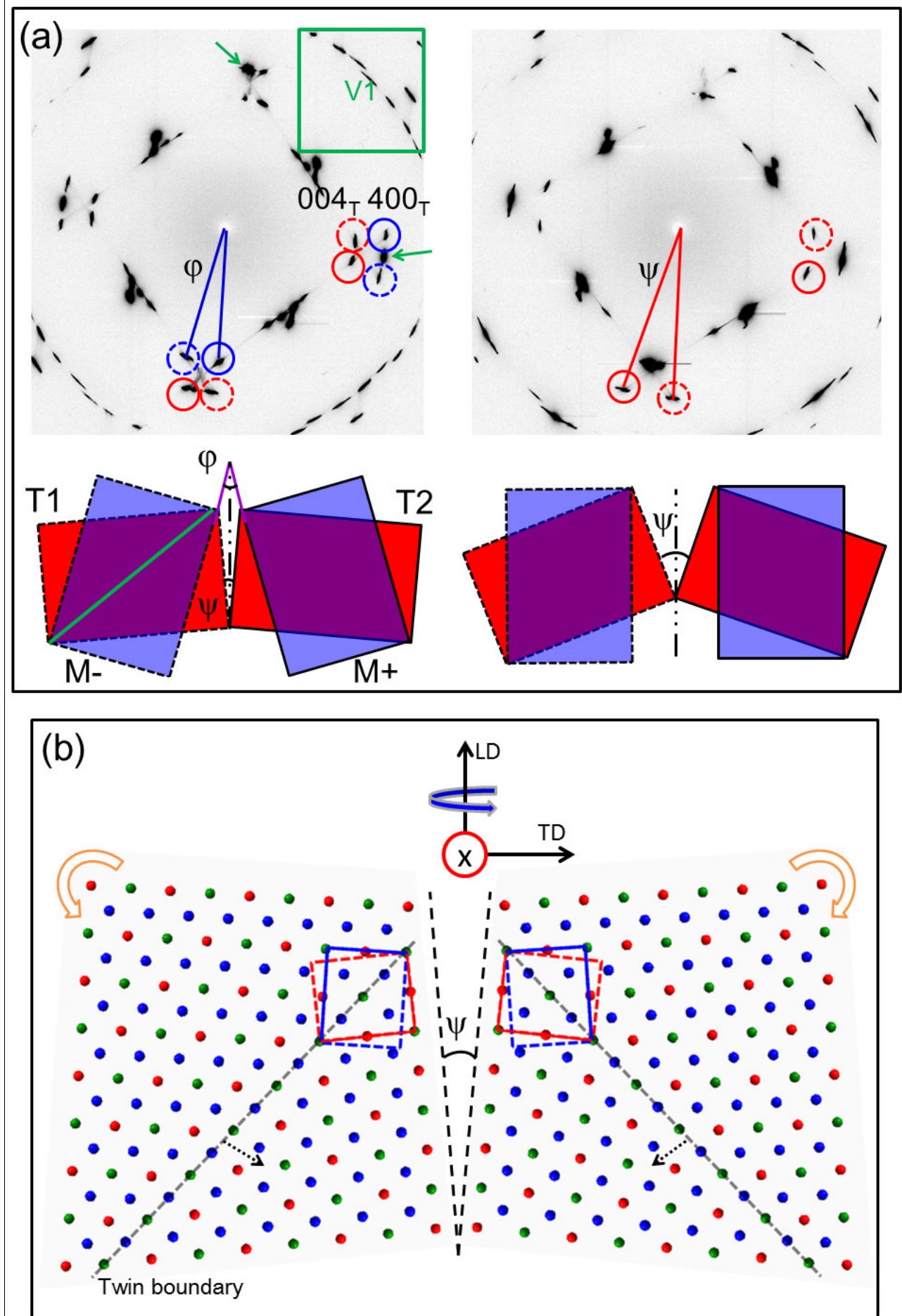

Fig. 9 (a) Diffraction patterns indexed with three kinds of variants before loading (left) and at the maximum applied strain (right). (b) Schematic for the lattice rotation and variants reorientation at the atomic scale. 


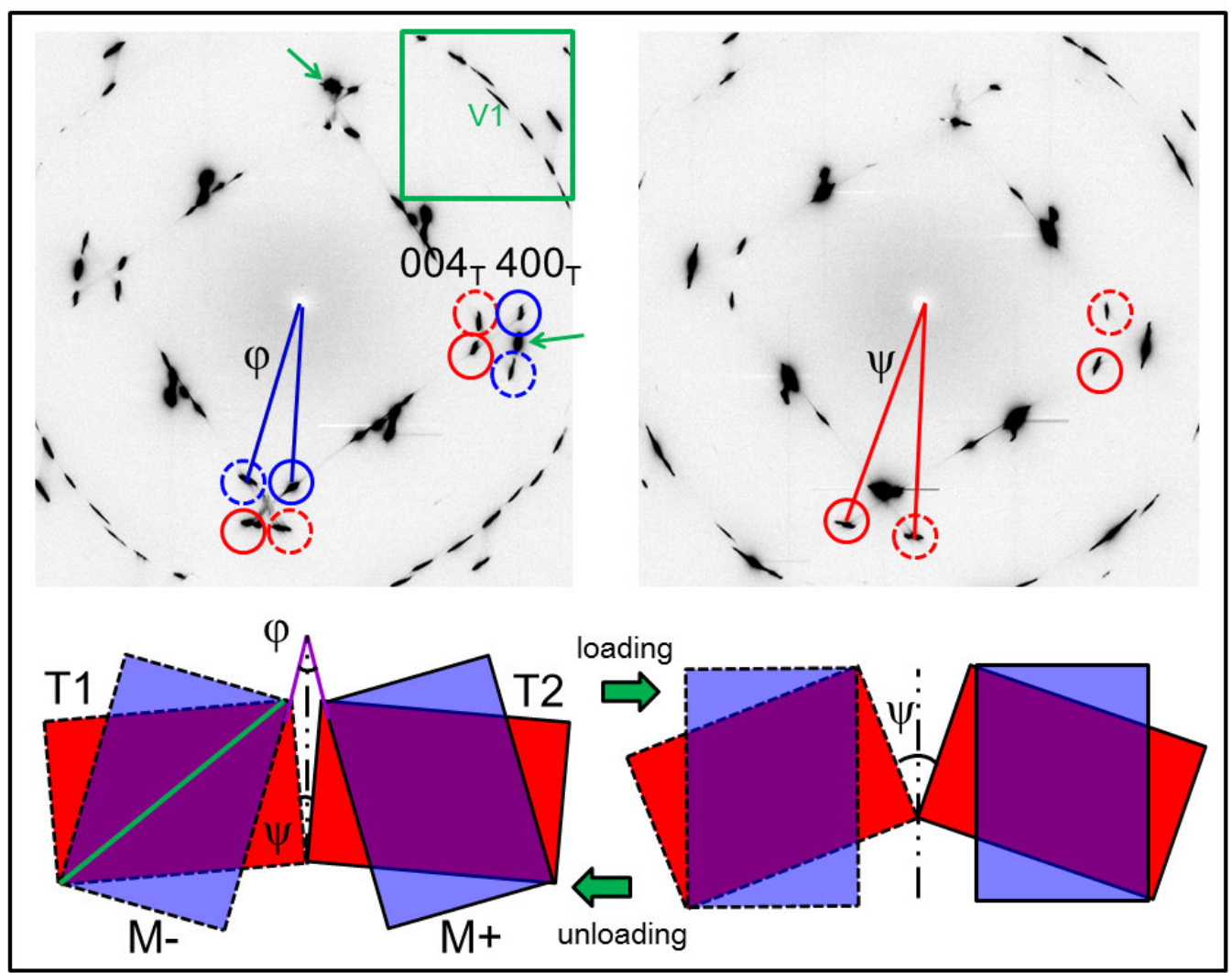

Graphical abstract 